\begin{tabular}{cc} 
ACADEMIA ROMÂNĂ & Rev. Roum. Chim., \\
Revue Roumaine de Chimie & 2019, 64(4), 299-310 \\
http://web.icf.ro/rrch/ & Doi: $10.33224 /$ rrch.2019.64.4.02 \\
\hline
\end{tabular}

\title{
ADSORPTION OF RIMSULFURON IN SELECTED SOILS AND ITS REMOVAL VIA ACTIVATED CARBON
}

\author{
Khuram Shahzad AHMAD* \\ ${ }^{\mathrm{a}}$ Department of Environmental Sciences, Fatima Jinnah Women University, The Mall, 46000, Rawalpindi, Pakistan
}

Received July 24, 2017

\begin{abstract}
In present investigation, Rimsulfuron has been adsorbed onto the selected soils possessing agricultural significance via batch equilibration experiments. Such an approach was adopted for comprehension of the adsorptive interactions between Rimsulfuron and soils as a function of selected soils'physicochemical parameters. Linear adsorption coefficient $\mathrm{K}_{\mathrm{d}}$ values varied from 3.07 to $20.5 \mu \mathrm{g}$ $\mathrm{mL}^{-1}$. Due to distinct physicochemical properties favoring the adsorption of Rimsulfuron, highest $\mathrm{K}_{\mathrm{d}}$ value was shown by soil sample three with highest organic matter of $1.4 \%$ and lowest $\mathrm{pH}$ of 7.05. The Gibbs free energy values were found negative ranging from -6.7 to $-19 \mathrm{~kJ} \mathrm{~mol}^{-1}$ proposing physio-sorption and exothermic interaction with selected soils. Results have been statistically analyzed by one way analysis of variance (ANOVA) and the accuracy of fit has been calculated by plotting residual graphs in Minitab. Activated carbon has been utilized for environmental remediation of Rimsulfuron adsorbed soils in simulated conditions. The effect of contact time on the removal efficiency was investigated. Soil sample 2 expressed the highest removal percentages by activated carbon at both concentrations of $5 \mathrm{ppm}$ $(81 \%)$ and $7.5 \mathrm{ppm}(69 \%)$.
\end{abstract}

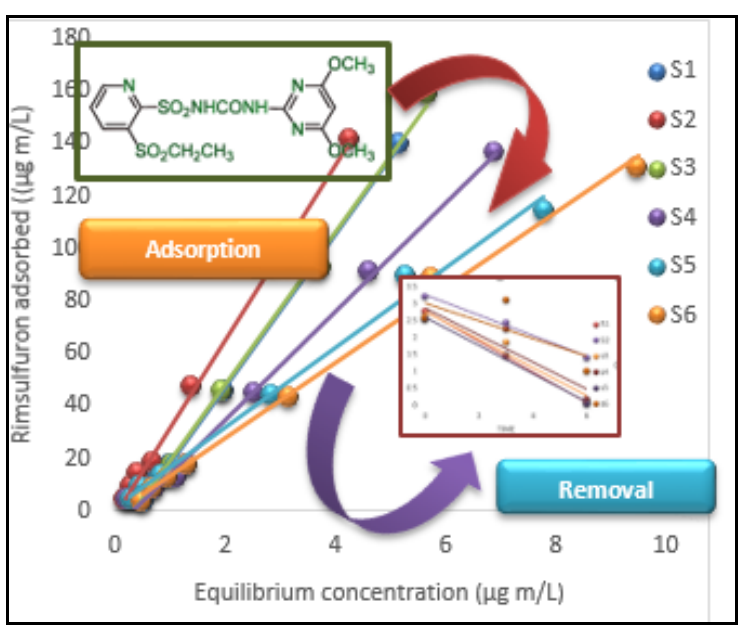

\section{INTRODUCTION}

Good agricultural yield is dependent on a variety of chemicals synthetically prepared e.g. chemicals aimed at killing fungi, weeds, insects and other obnoxious entities. In agricultural practices, pesticides are widely used control pests, disease, weeds and other plants pathogens. Utilization of such synthetically prepared chemicals has become a practice on daily basis in different agricultural regions. Weed control is an imperative factor for an effective crop production and therefore the prevention of weed-crop competition at an early stage plays a very paramount role. The key role played by pesticide is to reduce or eliminate yield losses and to maintain high product quality. Such unjust use has given rise to environmental pollution. Transport of pesticide residues into soil and other environmental components not only effects the physical components of the environment but affects all living organisms from vertebrates to microbial communities.

Apart from the indiscriminate use of pesticides in agricultural sector, the widespread use of such chemical for maintenance of urban green lands in form of laws has also been gaining momentum. During the last several decades use of agricultural pesticides has rapidly increased but the long-term fate and transfer dynamics of agricultural

\footnotetext{
*Corresponding author: chemist.phd33@yahoo.com; dr.k.s.ahmed@fjwu.edu.pk; Tel \#: +92-51-9292900 (162)
} 
pesticides in a changing environment are poorly understood. Thus, urban landscapes also needs thorough investigation in this regard as in case of agricultural lands being polluted by pesticides. So far researchers have been investigating the pollution of soils with different pesticides in artificially prepared matrices in simulated conditions. Such experiments are designed to closely resemble the real agricultural soils contaminated with the agrochemicals. The destiny and qualities of pesticides in soils and filtering to profound soil vacillate with soil physio-chemical properties. ${ }^{1}$ The usage of agricultural pesticide has controlled pests in Pakistan, but these pesticides are causing serious environmental problems and due to the frequent agricultural pesticide usage, many areas of Pakistan are being under the detrimental effects of pesticide contamination. Though the ecological impacts associated with the widespread use of different pesticides have been investigated. $^{3-4}$ Yet there is a major obstacle towards establishing clear environmental trends in Pakistan due to lack of comprehensive researches on all agrochemicals being used.

From the mid-1980s, Sulfonylurea (SU) herbicide has been frequently used for postemergent weed control in agriculture. Sulfonylurea is one of the most important classes of herbicides, and currently this family is the most commercial class of related herbicides and has been extensively developed. It is of great importance because of ultra-low dosage application, low mammalian toxicity and an outstanding herbicidal activity. Long time applications of sulfonylurea herbicides regularly cause curtailment in crop yield yearly in addition to emergence of resistant weed species to herbicides applications. When a pesticide is applied on a specific area relative oxides are formed. These ions react with water which then mix with soil and create fertility problem by increasing or decreasing the $\mathrm{pH}$ of soil depending on the nature of compound as compared to other classes of pesticides herbicides are less baneful.

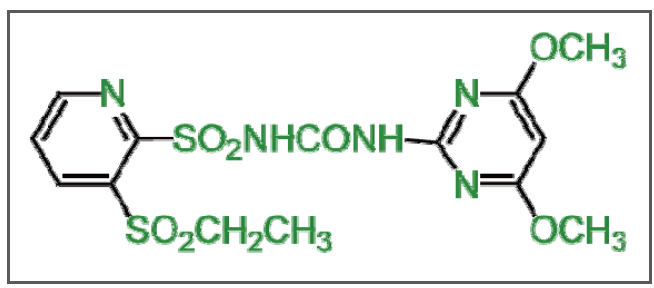

Fig. 1 - Chemical structure of Rimsulfuron.

Rimsulfuron [N-((4,6-dimethoxypyrimidin-2yl)aminocarbonyl)-3-(ethylsulfonyl)-2-pyridine-sul- fonamide] $\left(\mathrm{C}_{14} \mathrm{H}_{17} \mathrm{~N}_{5} \mathrm{O}_{7} \mathrm{~S}_{2}\right)$ is a recent herbicide belongs to the group of sulfonylurea herbicides. By reaction of 2-sulfamoylchloride-3-sulfonylethylpyridine with 2-amino-4,6-dimethoxypyrimidine Rimsulfuron is produced. It is a colorless crystal having melting point of $176-178^{\circ} \mathrm{C}$. Its water solubility rises from about $0.1 \mathrm{~g} / \mathrm{L}$ at $\mathrm{pH} 5$ to about 6-7 $\mathrm{g} / \mathrm{L}$ at $\mathrm{pH} 7.9$ and it is an acid, pKa 4.0. Closely resembling other sulfonylurea herbicides, Rimsulfuron additionally assaults the enzyme acetolactate synthase (ALS) which is in charge of generation of amino acids. Rimsulfuron hinders this catalyst which significantly diminishes the generation of expanded chain amino acids. Several agricultural crops e.g. tomatoes, corn, potatoes etc. have been protected against different weeds by Rimsulfuron. The use of Rimsulfuron has been hastened as soon as it was commercialized due to some characteristics e.g. lower dosages, increased weedicidal activity, functional specificity in addition to lower toxicity levels.

Closely resembling other sulfonylurea herbicides, Rimsulfuron additionally assaults the enzyme acetolactate synthase which is in charge of generation of amino acids. Rimsulfuron hinders this catalyst which significantly diminishes the generation of expanded chain amino acids. ${ }^{5}$ Because of superb adsorptive characteristics of activated carbon it has been broadly applied in different industries for removing toxicity from various products and purifying and de-coloring materials. Adsorption on activated carbon is an extremely potential method for eliminating many micro pollutants.

Pakistan is an agricultural economy and has been endowed with fertile agricultural lands. This is why Pakistan has been known in international market for wide variety of export quality crops. But Pakistani soils enriched with nutrients are equally exposed to environmental contamination caused due to the use of pesticides. Such alterations caused in soils can be comprising of both physicochemical transformations and soil biota alteration. Thus, where there are wide scale researches done of enhancing the herbicidal efficacy, there is a dire need for researches regarding the consequent environmental impacts safety. In Pakistani soils, no work has been reported for the Rimsulfuron adsorption and removal from the selected soils. Thus, the objective of this research was to investigate the interaction of Rimsulfuron with agricultural soil and physiochemical properties of soil. In addition, presented work is also aimed the introduction of 
cost effective method to investigate the adsorptive characteristics and efficiency of the activated carbon made of Cedrus deodara sawdust (CDS) for the pesticide removal. Current work opens a myriad of options for future researches regarding the ecological risk assessment of Rimsulfuron in selected soils.

\section{RESULTS AND DISCUSSION}

Chemical properties of soil may adversely affect by the use SU herbicides as well as the species diversity in an agro-ecosystem has also been declined due to these herbicides besides causing changes in structure and behavior of weed populations..$^{6-8}$ For the solution of weed problem the use of SUHs remained a challenging issue among scientific community. However one of the major challenges that hinder the development and application of this class of herbicides is the longer degradation period of $\mathrm{SU}$ due to its longer persistent in soil. ${ }^{9-10}$ On the other hand the high water solubility behavior of Sulfonylurea herbicides results in high mobility and risk of transfer to surface water bodies. The application of pesticides results in the formation of relative oxides on the specific soil. After the reaction of ions with water in a soil it causes the increase or decreases in the $\mathrm{pH}$ of soil and creates fertility problem. The change in soil condition depends upon the nature of compound used. This is the reason why the herbicides (classes of pesticides) are less baneful.

In Pakistan numerous types of herbicides, fungicides, rodenticides and insecticides are being currently applied for crop protection. The usage of agricultural pesticide has controlled pests in Pakistan, but these pesticides are causing serious environmental problems and due to the frequent agricultural pesticide usage, many areas of Pakistan are being under the detrimental effects of pesticide contamination. The pesticides do not persist for long time in soil of Pakistan and leach to groundwater. Pesticides poisoning cause severe health problems in Pakistan. ${ }^{11-13}$ Environmental pollution caused due to agrochemicals has been closely associated with the indiscriminate use. Farmer community is of the view that greater inputs might result in greater yield, however they are completely unaware of the consequent ecological imbalance caused. Variety of researches have been done on the adsorption of different pesticides in soils. ${ }^{14-18}$ Despite such studies, reports regarding Rimsulfuron in Pakistani soils selected for current research are nonexistent. Current research has tackled the adsorption of Rimsulfuron with selected soils as physical adsorbents in addition to the environmental detoxification of those soils by means of biosorbent prepared in a cost effective and environmental friendly assay. Such an approach signifies the use of CDS as a completely novel material for Rimsulfuron removal. Results are also suggestive of employing the CDS for Rimsulfuron removal on a commercialized scale with negligible costs. Furthermore, results also revealed that Rimsulfuron interaction with soils is affected by soils' physicochemical parameters. Rimsulfuron adsorption in selected soils was evaluated with linear and Freundlich model for thorough comprehension of the surficial chemistry between soils and Rimsulfuron. While, CDS was analyzed via FTIR for confirmation of the interplay of different functional groups in CDS for Rimsulfuron mitigation.

Table 1

Physiochemical analysis of soil samples

\begin{tabular}{|c|c|c|c|c|c|c|c|c|c|c|}
\hline \multirow[t]{2}{*}{ No. } & \multirow[t]{2}{*}{ Sample } & \multirow[t]{2}{*}{ pH } & \multirow[t]{2}{*}{$\mathbf{O M}$} & \multirow[t]{2}{*}{ Saturation } & \multirow[t]{2}{*}{ Texture } & \multirow{2}{*}{$\begin{array}{l}\begin{array}{l}\text { Texture } \\
\text { Classes }\end{array} \\
\text { Sand }\end{array}$} & \multicolumn{2}{|c|}{$\begin{array}{l}\text { Electrical } \\
\text { conductivity } \\
\mu \mathrm{S} / \mathrm{cm}\end{array}$} & \multirow[t]{2}{*}{$\begin{array}{l}\text { Total } \\
\text { carbon } \\
\%\end{array}$} & \multirow[t]{2}{*}{$\begin{array}{l}\text { Total } \\
\text { nitrogen } \\
\%\end{array}$} \\
\hline & & & & & & & Silt & Clay & & \\
\hline S1 & Taxila & 7.62 & 1.15 & 50 & Clay Loam & 44 & 39 & 17 & 280.0 & 0.66 \\
\hline S2 & Karachi & 7.44 & 0.70 & 26 & Sandy Loam & 83 & 3.0 & 15 & 2120 & 0.41 \\
\hline S3 & Peshawar & 7.05 & 1.40 & 29 & Clay Loam & 45 & 41 & 15 & 397.0 & 0.81 \\
\hline S4 & Attock & 7.68 & 1.10 & 50 & Loam & 54 & 36 & 10 & 143.4 & 0.64 \\
\hline S5 & Chakwal & 7.28 & 1.25 & 50 & clay Loam & 53 & 38 & 9.0 & 291.0 & 0.72 \\
\hline S6 & Kotli & 7.62 & 1.35 & 48 & Silty clay loam & 3.0 & 63 & 35 & 334.0 & 0.17 \\
\hline
\end{tabular}


Table 2

Linear and Freundlich model parameters

\begin{tabular}{l|l|l|l|l|l|l|l|l|l}
\hline Sample & $\begin{array}{l}\mathbf{K}_{\mathbf{d}} \\
(\boldsymbol{\mu g} / \mathbf{m L})\end{array}$ & $\mathbf{R}^{2}$ & $\begin{array}{l}\mathbf{K}_{\mathbf{o m}} \\
(\boldsymbol{\mu} \mathbf{g} / \mathbf{m L})\end{array}$ & $\begin{array}{l}\Delta \mathbf{G} \\
(\mathbf{k J} / \mathbf{m o l})\end{array}$ & $\begin{array}{l}\mathbf{K}_{\mathbf{o c}} \\
(\boldsymbol{\mu g} / \mathbf{m L})\end{array}$ & $\begin{array}{l}\mathbf{K}_{\mathbf{f}} \\
(\boldsymbol{\mu g} / \mathbf{m L})\end{array}$ & $\mathbf{R}^{2}$ & $\begin{array}{l}\mathbf{K}_{\text {foc }} \\
(\boldsymbol{\mu g} / \mathbf{m L})\end{array}$ & $\mathbf{n a}$ \\
\hline S1 & 6.50 & 0.89 & 677.0 & -16 & 415.0 & 3.42 & 0.83 & 140 & 0.69 \\
S2 & 19.4 & 0.91 & 1500 & -6.7 & 864.0 & 3.16 & 0.70 & 227 & 0.78 \\
S3 & 20.5 & 0.96 & 2881 & -19 & 135.3 & 3.42 & 0.97 & 140 & 0.69 \\
S4 & 9.87 & 0.91 & 1135 & -17 & 652.0 & 2.31 & 0.97 & 152 & 0.74 \\
S5 & 3.07 & 0.88 & 215.4 & -15 & 249.2 & 3.22 & 0.86 & 451 & 0.36 \\
S6 & 6.34 & 0.89 & 857.1 & -16 & 107.2 & 1.04 & 0.92 & 140 & 0.47 \\
\hline
\end{tabular}

\section{Adsorbent 1 physicochemical parameters}

Soils are formed under different condition due to which their physicochemical make up is distinctively variable from one another (Table 1). For example soils formed following a chemical weathering will be different from those soils which have been formed following a volcanic eruption. Such variations can be physical i.e. color, $\mathrm{pH}$, texture, or can be chemical i.e. nutrients, heavy metals, organic matter (OM). Soils' physicochemical parameters are predictive of various factors. ${ }^{19}$ Current work has explored soils' physicochemical parameters in order to predict the adsorption of Rimsulfuron as a function of soils' make up. Results have revealed that all selected six soils have different make ups. Soils varied from one another in $\mathrm{pH}$. Soil sample 3 has shown the lowest $\mathrm{pH}$ among all samples. Lowest $\mathrm{pH}$ can be result of various climatic activities in the selected regions e.g. higher precipitation rates during monsoon, an elevated presence of microbial communities adaptive to slightly acidic $\mathrm{pH}$ etc. Soils' $\mathrm{pH}$ has been known for affecting the adsorption of various chemicals. ${ }^{20,21}$ Another important physical factor playing an influential role in Rimsulfuron adsorption is the soils' texture. Textural classification predicts soil sample 6 to be best adsorbent of Rimsulfuron due to possession of higher quantity of silty clayey soil. But, adsorption is not solely dependent upon soils' clay content thus taking into account soil organic matter (SOM) is a crucial step in comprehending Rimsulfuron adsorption in soils. Various soil based phenomenon are responsible for the formation of organic matter in soils. Pakistani soils, though being very rich in nutrients are devoid of higher SOM quantities. That is why various organic treatments have been done to compensate for SOM for good agricultural yield. ${ }^{22}$ However, irrespective of this factor whether organic amendment has been done or not, the inherent SOMs have profound effect on Rimsulfuron adsorption in soils. In this case, soil sample 3 exceeds all soils in having $1.40 \%$ of SOM. Consequently it also exhibits $0.81 \%$ of organic carbon.

\section{Adsorption models}

Rimsulfuron adsorption in selected soils was evaluated via linear and Freundlich models for comprehending the multilayer adsorption pattern. Adsorption isotherms (Table 2, Figs. 2, 3) have been plotted by taking Rimsulfuron adsorbed on $\mathrm{Y}$-axis and equilibrium concentration on $\mathrm{X}$-axis. Adsorption isotherms exhibited C-type isotherm. C-type isotherm shows the partitioning phenomenon between the Rimsulfuron molecules and soil particles being distributed at the interface without the interplay of any type of typical bonding mechanisms. Various soil based studies have yielded different shaped isotherms. ${ }^{23}$ The isotherms obtained provided with the information of distribution coefficient $\left(\mathrm{K}_{\mathrm{d}}\right)$, Freundlich constant $\left(\mathrm{K}_{\mathrm{f}}\right)$ and Gibbs free energy $(\Delta \mathrm{G})$.

\section{Linear and Freundlich model}

Linear model was applied on Rimsulfuron adsorbed soils via batch equilibrium method in which Rimsulfuron was tested in a concentration dependent manner. The concentration of Rimsulfuron was measured in the soil dilutions and mass difference between starting and equilibrium phase was considered as adsorption. Linear adsorption co-efficient $\left(\mathrm{K}_{\mathrm{d}}\right)$ and other parameters were derived for Rimsulfuron adsorption (Table 2). The 
value of distribution constant $\mathrm{K}_{\mathrm{d}}$ varied from 3.07 to $20.5 \mu \mathrm{g} \mathrm{mL}^{-1}$. The highest value for adsorption co-efficient was observed for soil sample 3 among all other treated soil samples. Maximum adsorption by soil 3 was due to the highest organic matter of $1.4 \%$ and lowest $\mathrm{pH}$ of 7.05 among all soil samples. The values of $\mathrm{R}^{2}(0.88-0.96)$ shows that the adsorption results are best fitted to linear adsorption model. The Freundlich adsorption co-efficient $\mathrm{K}_{\mathrm{f}}$ represents the sorption capacity of Rimsulfuron in selected soils. $K_{f}$ values for adsorption of Rimsulfuron ranges between 1.04 and $3.42 \mu \mathrm{g} \mathrm{mL}^{-1}$.

Rimsulfuron exhibited medium mobility signifying relatively lesser chances of leaching. The highest $\mathrm{K}_{\mathrm{oc}}$ value was observed at soil sample $2\left(864.0 \mu \mathrm{g} \mathrm{mL}^{-1}\right)$. The thermodynamic parameter Gibbs free energy $(\Delta G)$ expressed negative values ranging from -6.7 to -19 . $\mathrm{kJ} \mathrm{mol}^{-1}$. Its negative values indicated that the Rimsulfuron-soil interaction is spontaneous as well as exothermic. This evaluation also indicates that Rimsulfuron became virtually adsorbed on all soil samples through weak forces called Van der Waals forces. Other pesticides e.g. Siduron has also exhibited the same bonding behavior through negative vales of $-11 \mathrm{~kJ} \mathrm{~mol}^{-1}$ signifying the presence of physiosorption between Siduron and selected soils. ${ }^{24}$ Similarly investigations on carbaryl and parathion adsorption have also exhibited weaker forces operating between soils and pesticide molecules. Both linear and Freundlich models of Rimsulfuron adsorption in soils have signified the interplay of various phenomenon e.g. Rimsulfuron transportation revealed from $\mathrm{K}_{\mathrm{oc}}$ values, Rimsulfuron degradation revealed from lower $\mathrm{pH}$ of soils where there can be a possible presence of

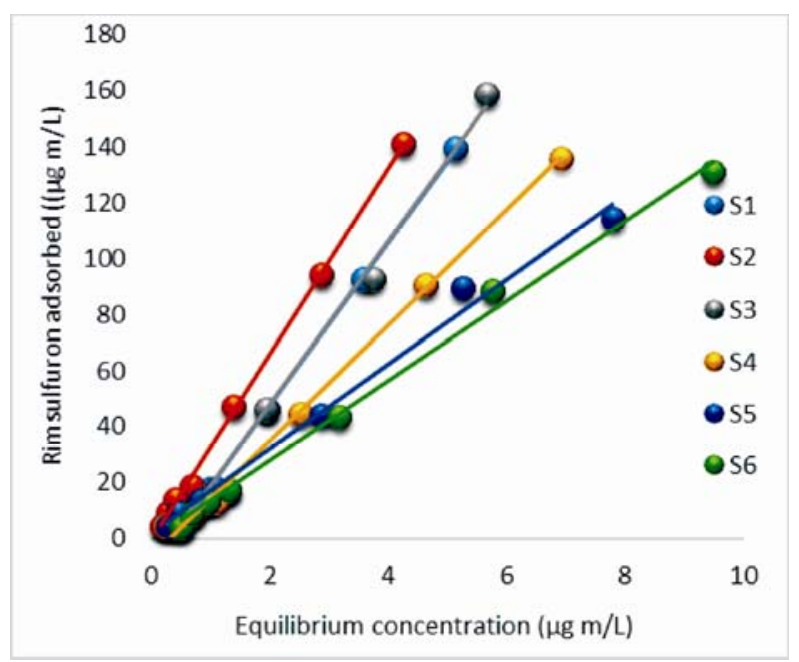

soil microbial biota. Furthermore, the translocation factor is revealed again from $\mathrm{K}_{\mathrm{oc}}$ values because if the values are higher, then Rimsulfuron molecules might be prevented from entering soil profiles and will be consequently transferred to plant parts via translocation.

Higher distribution of Rimsulfuron in soil sample 3 can be attributed to the clay content. Since clays comprise of the weakly hydrated cations, thus if the size of the hydrated cation is smaller, it gives rise to the higher adsorptive interactions between exchangeable cations and Rimsulfuron molecules. Soils are composed of bulk materials about $50 \%$ while rest of soil being the air and water content. Among the bulk materials, soil clay content and organic matter have been found influential in affecting adsorption of Rimsulfuron in selected soils. ${ }^{25}$ Furthermore, clays role in adsorbing Rimsulfuron can be comprehended from the presence of negative sites which attract the organic compounds in bridging via water molecules.

In addition to various factors affecting the Rimsulfuron adsorption in selected soils, the role or organic matter cannot be neglected. SOMs are known for controlling the pesticides fate in soils thus Rimsulfuron transport, fate, leaching and degradation are partly controlled by SOM. Different investigations suggest that OM addition or any other type of organic amendment will enhance the pesticides' adsorption to soils. Current results are also suggestive of the fact that soil sample 3 with higher organic matter content seems to be inducing modifications in Rimsulfuron leaching pattern and consequent contamination of ground water reserves. ${ }^{26}$

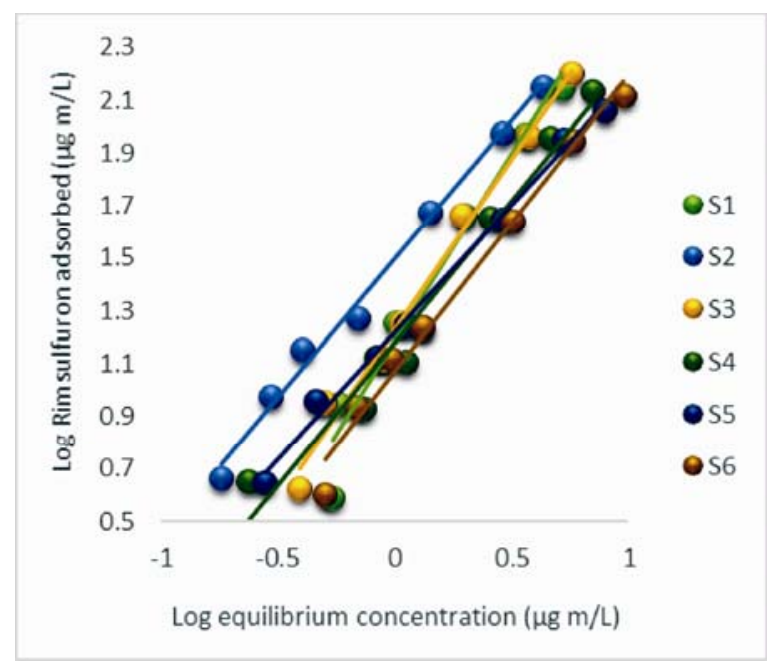

Fig. 2 - Comparative graph expressing the adsorption of Rimsulfuron via linear and Freundlich model. 

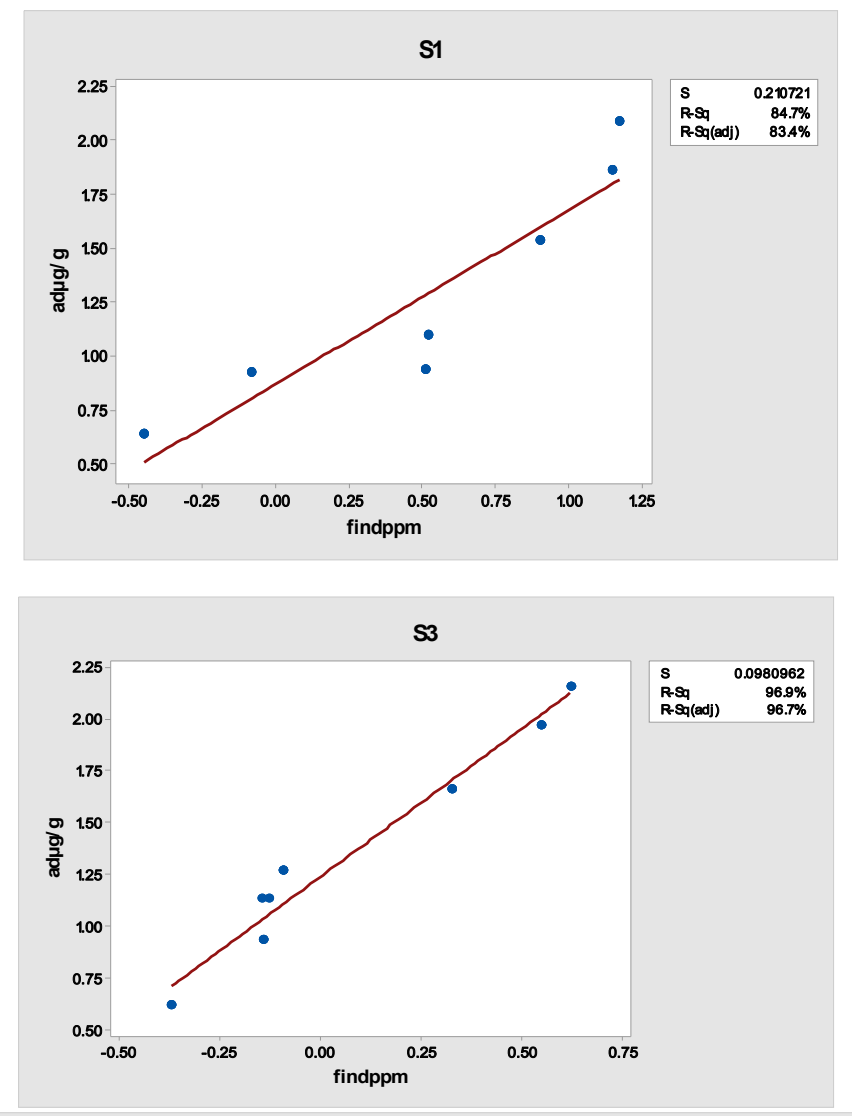

S5

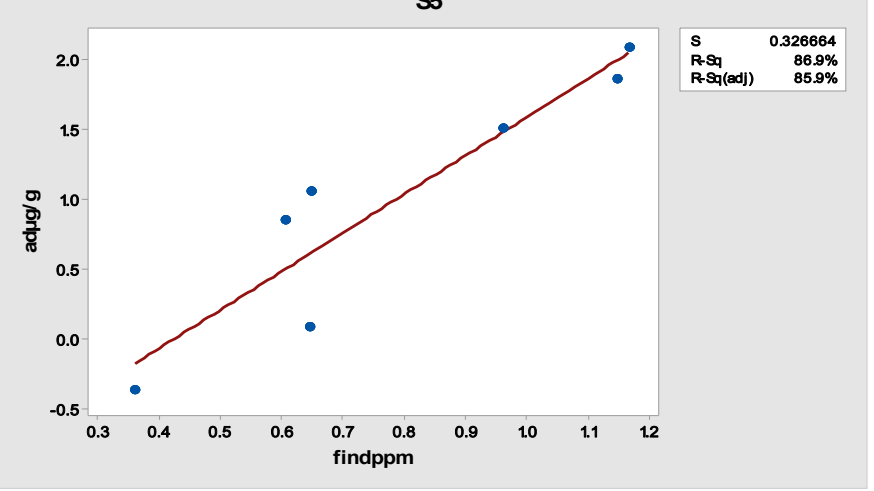

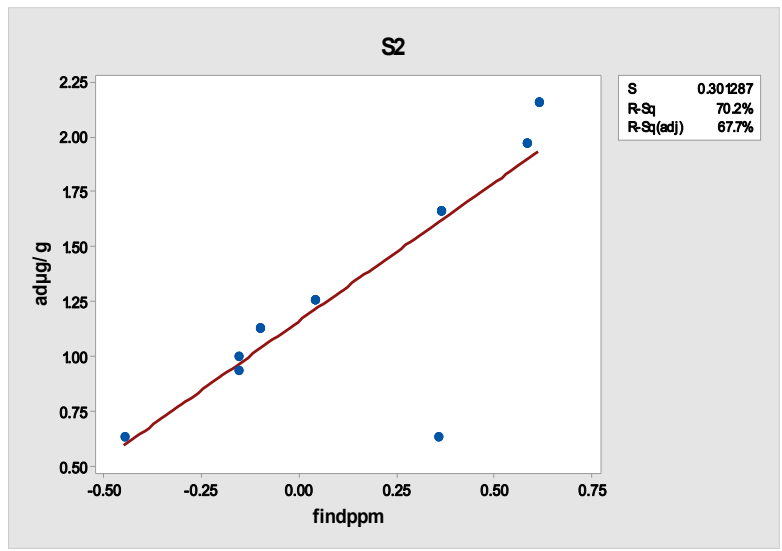

S4

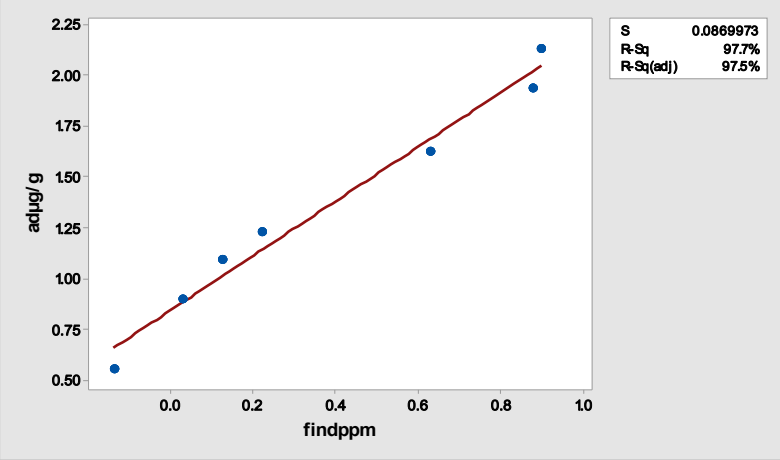

S6

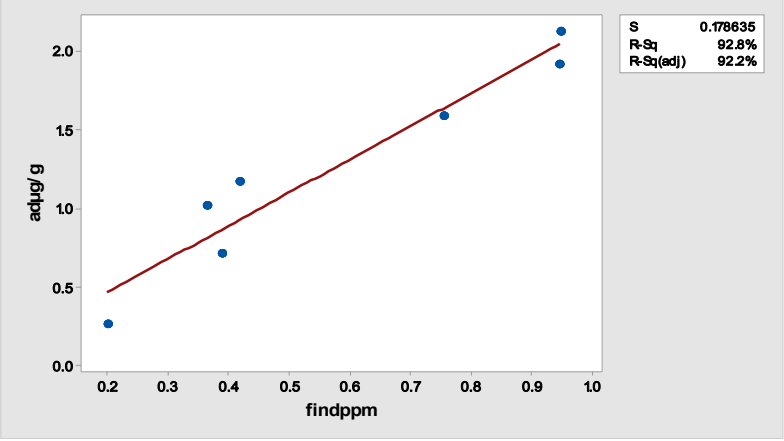

Fig. 3 - Isothermal representation of Rimsulfuron adsorption in selected soils.

\section{Rimsulfuron percolation pattern}

The role of soils' physicochemical make up is also equally significant in Rimsulfuron's mobility in the selected soils. Rimsulfuron percolation in subsequent soil profiles and entrance to ground water reserves can be easily comprehended from model parameters predominantly, $\mathrm{K}_{\mathrm{d}}, \mathrm{K}_{\mathrm{f}}$ and $\mathrm{K}_{\mathrm{oc}}$ Various studies done on SUHs expresses different percolation patterns for each herbicides. All SUHs are weaker acids with their disassociation constants ranging from 3.3 to 5.2. Previous studies defend the medium mobility of Rimsulfuron as found in the current research. Water sampling from groundwater reserves at two geographical locations for an extended period of 4-6 years has not expressed any Rimsulfuron residues. However, the results also points towards the fact that soil texture plays an important role in Rimsulfuron leaching. For example, sandy soils will quickly induce the leaching of Rimsulfuron through soil profile but clayey soil may cause a hindrance by closely binding to Rimsulfuron molecules. In the current results, soils having lesser affinity towards Rimsulfuron exhibiting less adsorption i.e. soil sample 5 may enhance the diffusion of Rimsulfuron by the transportation via thermal energy due randomized motions at molecular level. 
Percolation has also been studied by using the leaching model which expresses the possibility of higher leaching into deeper soil layer than the calculated ones. Such an alteration between calculated parameters and actual occurrence can be associated with the Rimsulfuron's preferential flow. Studies on the percolation of other pesticides e.g. napropamide have exhibited the role of dissolved organic matter in enhancing the leachability indices in soils that are amended with the sewage sludge.

Table 3

ANOVA analysis of Rimsulfuron adsorption on soils

\begin{tabular}{lllllll}
\hline Source of Variation & SS & Df & MS & F & P-value & F crit \\
\hline Between Groups & 454 & 3 & 151 & 11 & 0.0001 & 3.0 \\
Within Groups & 267 & 20 & 13 & & & \\
\hline
\end{tabular}
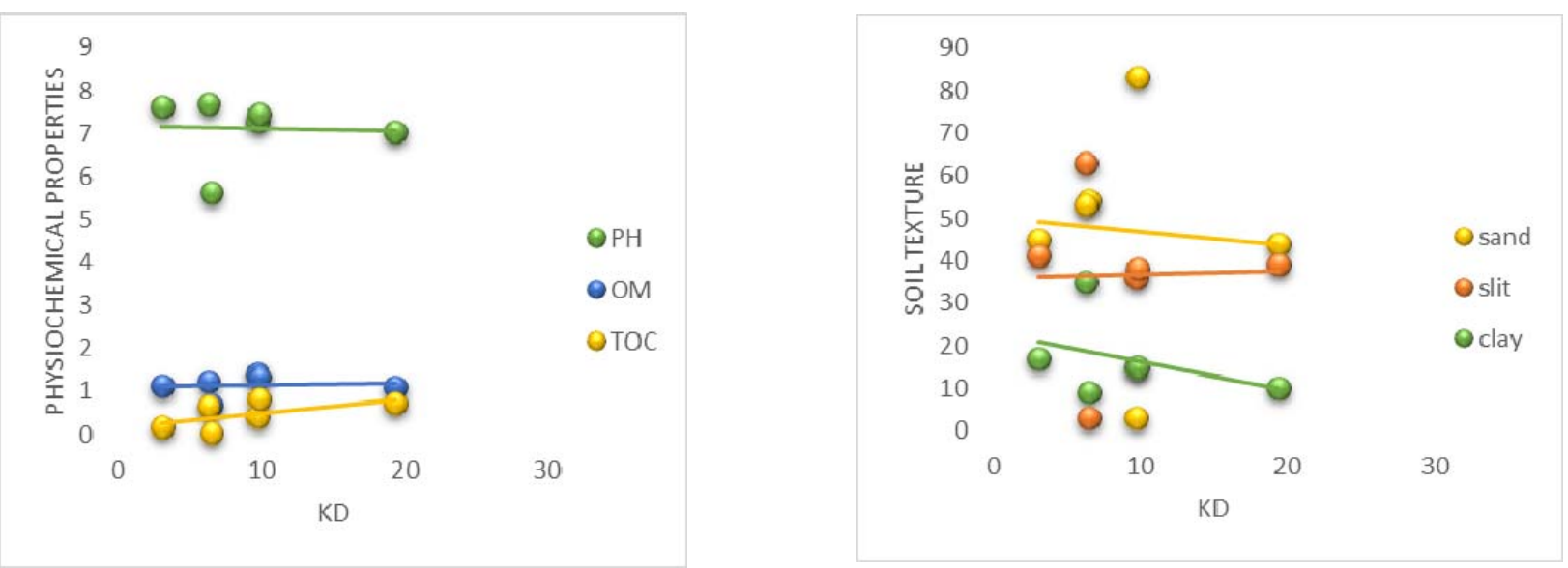

Fig. 4 - Correlation of Rimsulfuron adsorption with soils' physicochemical parameters.

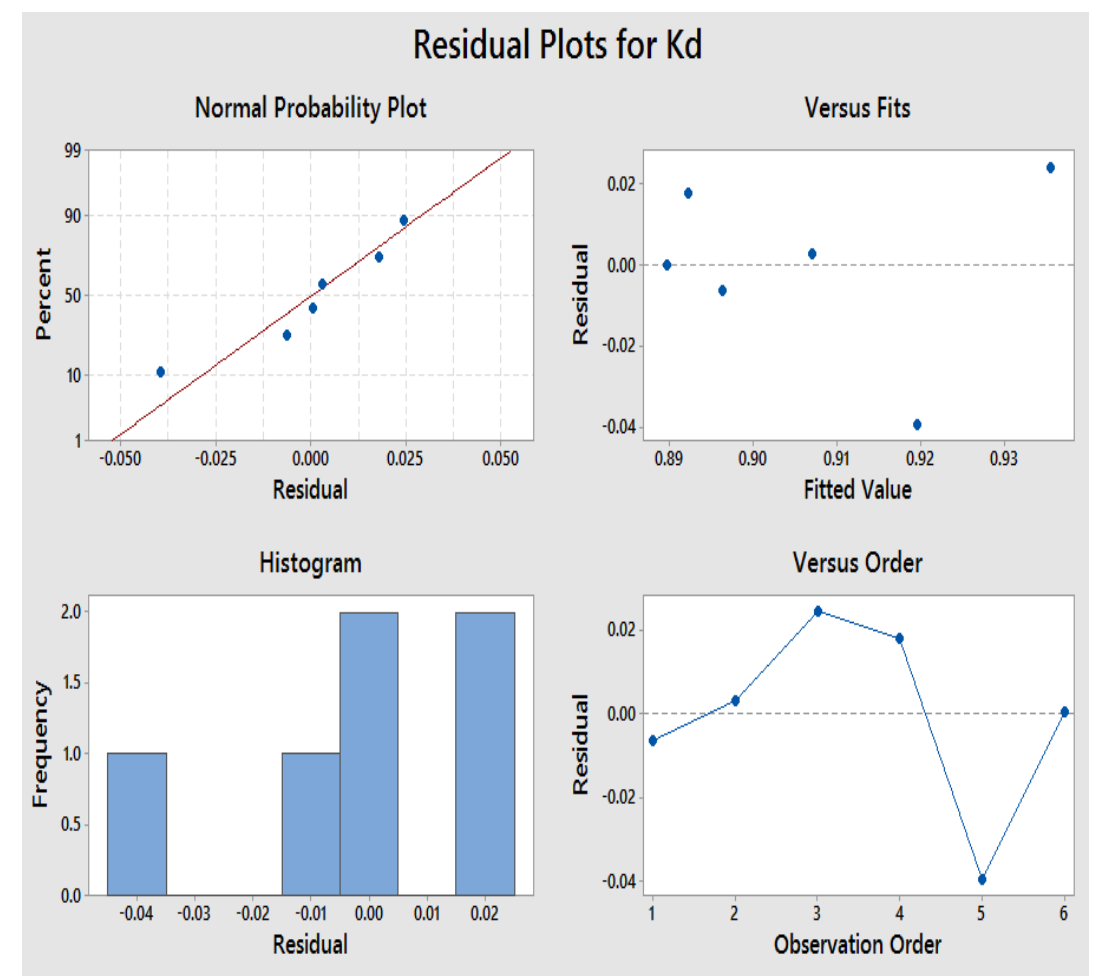

Fig. 5 - ANOVA Histogram, Versus Fit, Versus Order and Normal Probability Residual plots of soil samples with physiochemical properties $\mathrm{pH}, \mathrm{TOC}$ and $\mathrm{OM}$ while the response is $\mathrm{K}_{\mathrm{d}}$. 


\section{Correlative statistical significance}

Further statistical investigations were done regarding the relationship between $\mathrm{K}_{\mathrm{d}(\mathrm{ads})}$ and the physiochemical properties of soil including OM, TOC and $\mathrm{pH}$ (Fig. 4). The analysis proved that $\mathrm{pH}$ is negatively correlated to $\mathrm{K}_{\mathrm{d}(\mathrm{ads})}$ while $\mathrm{OM}$ and TOC were seen to be positively correlated. The lowering $\mathrm{pH}$ increase the adsorption of Rimsulfuron in soils and increase in adsorption was observed with the increasing percentage of $\mathrm{OM}$ and TOC. Current results expressing the correlative relationship between soils' physicochemical parameters and Rimsulfuron adsorption are consistent with previously done studies with other sulfonyl urea herbicides e.g. Metsulfuronmethyl, Sulfometuron-methyl, Nicosulfuron and Rimsulfuron in other soils. Such pattern has also been generalized for all sulfonyl urea herbicides.
Results were statistically evaluated via univariate ANOVA (Table 3, Fig. 5). The relationship of physiochemical properties of soils i.e. $\mathrm{pH}, \mathrm{OM}$ and TOC with $K_{d}$ was further assessed in Minitab 17 . The residual graphs plotted determined the goodness of fit in ANOVA. From these residual plots it is determined that the ordinary least square assumptions are being encountered. Sustaining these assumptions specifies that the ordinary least squares regression will produce unbiased coefficient estimates with the minimum variance. Normal probability plots of residuals, residuals versus fits and residuals versus order of data were plotted in Minitab (Fig. 5). Normal probability plot of residuals displays that our data is distributed normally. The residuals versus fits plot determines that the data has a constant variance.

Table 4

FTIR spectrophotometry of the adsorbate

\begin{tabular}{|c|c|c|c|c|}
\hline \multirow[t]{2}{*}{ Sr. no } & \multicolumn{2}{|c|}{ Before Activation by Acid } & \multicolumn{2}{|c|}{ After Activation by Acid } \\
\hline & Peak position & Functional Groups & Peak position & Functional Groups \\
\hline 1. & 800.49 & C-H "opp", & 561.30 & C-Br stretch \\
\hline 2. & 873.76 & N-H wag & 665.46 & $-\mathrm{C}=\mathrm{H}: \mathrm{CH}$ bend \\
\hline 3. & 1031.09 & $\mathrm{C}-\mathrm{O}$ stretch & 896.93 & $=\mathrm{C}-\mathrm{H}$ bend \\
\hline 4. & 1095.60 & C-O stretch & 1028.09 & C-N stretch \\
\hline 5. & 1207.48 & $\mathrm{C}-\mathrm{N}$ stretch & 1157.33 & $\mathrm{C}-\mathrm{O}$ stretch \\
\hline 6. & 1451.38 & $\mathrm{C}-\mathrm{H}$ bend & 1261.19 & C-H wag (-CH2X) \\
\hline 7. & 1614.47 & $\mathrm{~N}-\mathrm{H}$ bend & 1371.43 & C-H rock \\
\hline 8. & 2958.90 & $\mathrm{C}-\mathrm{H}$ stretch & 1425.51 & $\mathrm{C}-\mathrm{C}$ stretch (in ring) \\
\hline 9. & 3417.98 & $\mathrm{O}-\mathrm{H}$ stretch & 1510.31 & $\mathrm{~N}-\mathrm{H}$ bend \\
\hline 10. & ---- & ---- & 1732.13 & $\mathrm{C}=\mathrm{O}$ stretch \\
\hline 11. & ---- & ---- & 2018.40 & $-\mathrm{C}=\mathrm{C}$-stretch \\
\hline 12. & ---- & ---- & 3406.40 & $=\mathrm{C}-\mathrm{H}$ stretch \\
\hline
\end{tabular}

Table 5

Removal of Rimsulfuron by activated carbon from selected soils (5 ppm)

\begin{tabular}{lllllll}
\hline Samples & Location & $\begin{array}{l}\text { UV before } \\
\text { addition of } \\
\text { activated carbon }\end{array}$ & $\begin{array}{l}\text { UV after addition } \\
\text { of activated } \\
\text { carbon } \\
\text { (3 hours) }\end{array}$ & $\begin{array}{l}\text { UV after addition } \\
\text { of activated } \\
\text { carbon } \\
(6 \text { hours })\end{array}$ & $\begin{array}{l}\text { Average } \\
\text { removal }\end{array}$ & $\begin{array}{l}\text { Percentage } \\
\text { removal } \\
\%\end{array}$ \\
S1 & Attock & 2.768 & 1.467 & 0.054 & 0.7875 & 28.45 \\
S2 & Chakwal & 3.217 & 2.435 & 1.398 & 2.6155 & 81.30 \\
S3 & Karachi & 2.599 & 1.867 & 0.111 & 1.0445 & 40.18 \\
S4 & Taxila & 2.567 & 2.245 & 0.168 & 1.2905 & 50.27 \\
S5 & Peshawar & 2.543 & 1.476 & 0.039 & 0.777 & 30.55 \\
S6 & Kotli & 3.567 & 3.114 & 0.996 & 2.553 & 71.57 \\
\hline
\end{tabular}




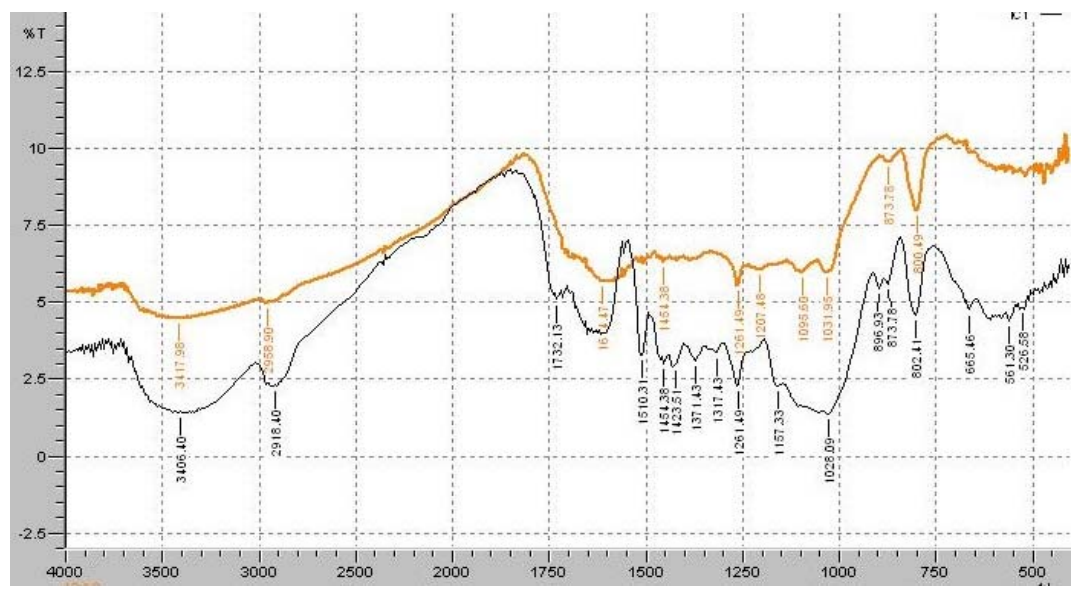

Fig. 6 - FT-IR spectrum of activated carbon sample.
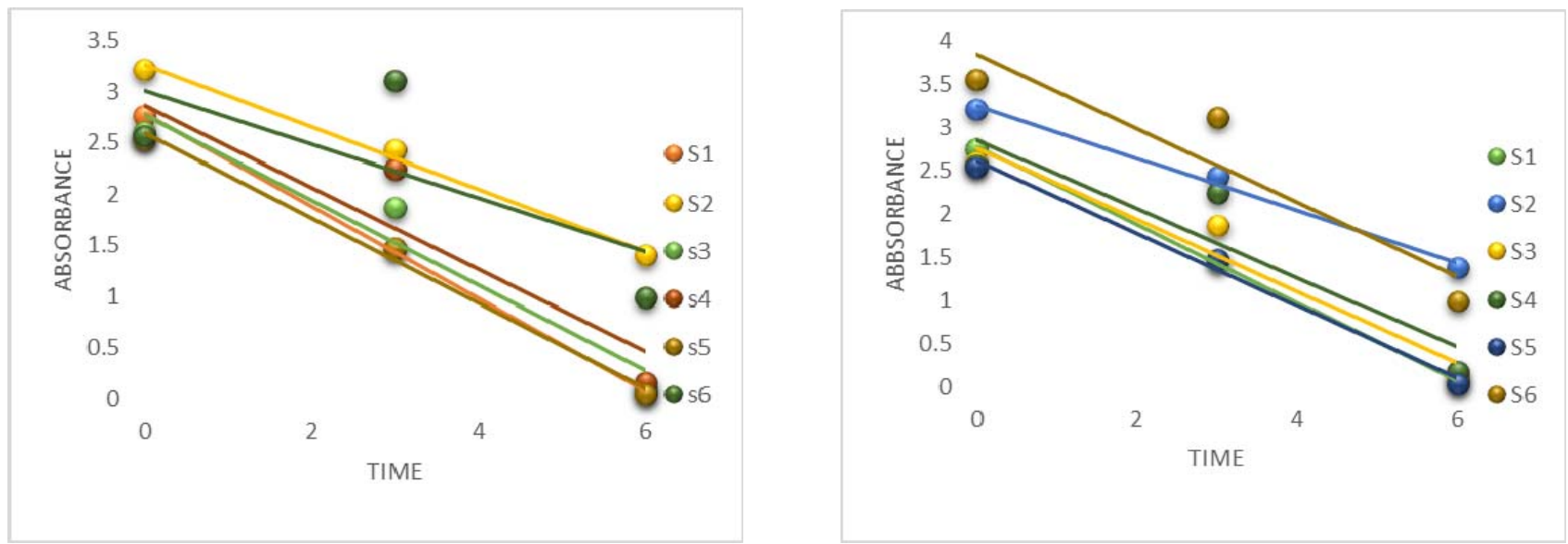

Fig. 7 - Comparative analysis of removal by activated carbon in selected soils (5 and $7.5 \mathrm{ppm})$.

\section{Activated carbon biosorbent analysis}

The enhanced use of herbicides in modern agriculture and absence of cost effective mechanisms has attracted the scientific community for devising modes that are ecofriendly and cost effective. Herbicides being transported through rainwater or irrigation to hydrospheric bodies can be dangerous. Thus, environmental friendly measures comprising of benign materials has been the priority of current era researchers. In this regard various materials have been prepared and tested soils. Though the remediation potential of CDS has been known for long proved by various investigations in which CDS was used as a biosorbent for removal of acid yellow-34. However, no reports are available on the evaluation of CDS as a biosorbent for Rimsulfuron removal. Thus current study has employed CDS for the effective removal of Rimsulfuron. CDS was analyzed using FT-IR spectrophotometry to analyze the active functional groups in the range of 400 to $4000 \mathrm{~cm}^{-1}$ that can act as an active site for the attachment of Rimsulfuron molecules for removal purpose (Table 4, Fig. 6). The number of functional sites were found to be increasing after activation indicating an increase in the sites for the attachment of Rimsulfuron. The present study explored the feasibility and removal mechanism for the mitigation of Rimsulfuron from selected soils using CDS (Tables 5, 6 and Fig. 7). Two initial concentrations were taken i.e. 5 and 7.5 ppm. The UV-Vis absorbance was checked before and after addition of CDS and after 3 and 6 hours results were analyzed then graphs were plotted comprising of the UV-Vis absorbance versus time using Microsoft Excel (2010). Highest removal percentages by CDS was shown by soil sample 2 at both concentrations of $5 \mathrm{ppm}(81 \%)$ and $7.5 \mathrm{ppm}$ $(69 \%)$. Soil sample 2 from Karachi had a high amount of sand content $(83 \%)$ which gave rise to poor adsorptive interactions between Rimsulfuron molecules and soils, thus making it easier for the CDS to remove more amount of Rimsulfuron from it due to weaker bonding. 
Table 6

Removal of Rimsulfuron by activated carbon from selected soils (7.5 ppm)

\begin{tabular}{lllllll}
\hline Samples & Locations & $\begin{array}{l}\text { UV before } \\
\text { addition of } \\
\text { activated carbon }\end{array}$ & $\begin{array}{l}\text { UV after addition of } \\
\text { activated carbon } \\
\text { (3 hours) }\end{array}$ & $\begin{array}{l}\text { UV after addition of } \\
\text { activated carbon } \\
\text { (6 hours) }\end{array}$ & $\begin{array}{l}\text { Average } \\
\text { removal }\end{array}$ & $\begin{array}{l}\text { Percentage } \\
\text { removal } \\
\%\end{array}$ \\
\hline S1 & Attock & 3.465 & 2.346 & 0.009 & 2.3505 & 67.83 \\
S2 & Chakwal & 3.043 & 2.190 & 1.011 & 2.106 & 69.20 \\
S3 & Karachi & 3.598 & 2.265 & 1.015 & 2.1475 & 59.68 \\
S4 & Taxila & 3.245 & 2.406 & 0.021 & 1.224 & 37.71 \\
S5 & Peshawar & 3.563 & 2.134 & 1.067 & 2.134 & 39.89 \\
S6 & Kotli & 3.067 & 2.121 & 0.899 & 1.9595 & 63.88 \\
\hline
\end{tabular}

\section{MATERIALS AND METHODS}

\section{Materials}

Analytical standard Rimsulfuron ([N-((4,6dimethoxypyrimidin-2-yl)aminocarbonyl)-3-(ethylsulfonyl)-2-pyridine-sulfonamide]) was purchased from Augsburg, Germany (99.9 \% pure) and was used without further purification. Acetone and methanol utilized were $99.9 \%$ pure. Anhydrous sodium chloride and calcium chloride were utilized as background electrolyte. Standard stock arrangement of the pesticide was set up in distilled water (DW).

\section{Instruments}

Weighting balance (ATx224, Shimadzu company), weighting machine (AUX220, Shimadzu company), orbital and incubator shaker (Irmeco Gmbh Germany), centrifuge (Sigma 26-E, Hettich Company), hot plate (MSH-20D, Wisestir instruments), atomic spectrophotometer (220, Varian company), UV-visible spectrophotometer (BMS1602), octagonal sieve shaker (Endecotts company), pH meter (WTW Ino Labs company) and EC meter (Crison company) were used in the experiments.

\section{Adsorbent 1: Soil preparation}

Four to five kg soil samples were sampled from six distinct territories of Pakistan. Taxila, Attock and Chakwal from Punjab, Peshawar from Khyber Pakhtoon Khawa, Kotli from Azad Kashmir and Karachi from Sindh province were selected. Sample collection was done in February, 2017 with the mean temperature of $25{ }^{\circ} \mathrm{C}$ over all regions. Samples were collected from specific points for each location through random sampling and stored in clean polythene bags and transported to laboratory. The soil samples were air-dried in the greenhouse for 2 days and sieved through a $2 \mathrm{~mm}$ mesh sieve to remove debris and large particles. ${ }^{27}$ For further experimentation and analysis samples were stored in labeled sterile petri dishes.

\section{Adsorption experiment}

All adsorption experiments were carried out in duplicate by using a standard batch equilibrium method. All experiments were done at laboratory isothermal conditions of $24-26^{\circ} \mathrm{C}$. The stock solution of Rimsulfuron was prepared in acetone. As per standard protocol stock solution of $10 \mathrm{ppm}$ of Rimsulfuron was prepared. Diluted solutions (0, $0.25,0.5,0.75,1,2.5,5$ and $7.5 \mathrm{ppm}$ ) were prepared from the stock solution, $100 \mathrm{~mL}$ of volumetric flask were labeled according to mentioned concentrations along with their duplicates. ${ }^{28} 10 \mathrm{~mL}$ of $0.1 \mathrm{M}$ sodium chloride solution was added to each dilution in order to maintain the ionic strength of soil as it acts as a background electrolyte. All samples along with duplicates plus blanks (no pesticide) and all the suspensions were shaken on a rotary shaker at $150 \mathrm{rpm}$ for a period of $48 \mathrm{~h}$. The vials were centrifuged for $20 \mathrm{~min}$ at $3500 \mathrm{rpm}$. $1 \mathrm{~mL}$ of the clear supernatant was removed, filtered by $0.2 \mu \mathrm{m}$ nylon filters and analyzed under UV-Vis spectrophotometer for the pesticide concentration determination in soils. Utilizing UV-Vis spectrophotometer (Model: BMS-1602), the concentration of Rimsulfuron in soil solution was analyzed. At UVVis spectrophotometer, the solutions were run at detection wavelength of $200-300 \mathrm{~nm}$ with water as the reference and Rimsulfuron was examined and distinguished by peak at $240 \mathrm{~nm}$.

\section{Adsorbent 2: Activated carbon preparation}

Cedrus deodara sawdust with known characteristics was collected from a local furniture 
market at Rawalpindi, Pakistan, at a price of 30 PKR per kg. The CDS was initially sieved and washed with DW for expulsion of possible dust particles. It was dried in the sunlight for 2-3 days followed by drying in oven at $150^{\circ} \mathrm{C}$ for $24 \mathrm{~h}$ for removal of moisture and other volatile impurities. After that it was crushed manually with mortar and pestle. Chemical activation of the powdered precursor was done with $99 \%$ conc. $\mathrm{H}_{2} \mathrm{SO}_{4}$ to make the impregnation ratio of $1: 1$. The slurry form of powder precursor was properly mixed and kept for $24 \mathrm{~h}$ for proper soaking. After that it was washed with cold distilled water and with normal DW to neutralize the $\mathrm{pH}$ of activated carbon and remove excess acid. It was then soaked in a $5 \%$ sodium bicarbonate solution and left for $24 \mathrm{~h}$. It was finally washed with cold distilled water till the solution became neutral. The powder was kept inside the oven at $110^{\circ} \mathrm{C}$ for $24 \mathrm{~h}$ and packed in an air tight container for further use as an adsorbent for removal of Rimsulfuron from contaminated soils. ${ }^{29}$

\section{Rimsulfuron loading on activated carbon analysis}

IR peaks were determined for the biosorbent i.e. CDS before and after loading of Rimsulfuron contaminated soils. IR measurements were done in the range of $400-4000 \mathrm{~cm}^{-1}$. For carrying out the FTIR study, the KBR palletization method was adopted. To form pellets pre-heated $\mathrm{KBr}$ in powder form was used. Prepared powder were well mixed with $\mathrm{KBr}$ with the help of mortar and pestle. The mixture then was subsequently given high pressure through the hydraulic pump. Activated carbon was analyzed using FT-IR spectrometry to analyze active functional groups in the range of 400 to $4000 \mathrm{~cm}^{-1}$ that can act as an active site for the attachment of pesticide. FT-IR spectrum was obtained before preparation of activated carbon i.e. raw material sawdust and after preparation of activated carbon and both spectra were compared. ${ }^{30}$

\section{Activated carbon driven Rimsulfuron removal}

For the detoxification of Rimsulfuron contaminated soils via CDS, dilutions of 5 and $7.5 \mathrm{ppm}$ had been prepared from $10 \mathrm{ppm}$ stock solution. $10 \mathrm{~mL}$ of each dilution was added in $15 \mathrm{~mL}$ of centrifuge tubes, along with $0.5 \mathrm{~g}$ of each soil sample and their absorbance was measured through UV-Vis spectrophotometer. Firstly, measurements were done before the addition CDS activated carbon. After that $0.5 \mathrm{~g}$ of CDS was weighed and added in every vial, shaken and left for $3 \mathrm{~h}$ before measuring absorbance for the establishment of equilibrium between the biosorbent i.e. CDS activated carbon and the target material. Same process was repeated for $6 \mathrm{~h}$ duration. ${ }^{31}$

\section{Data analysis}

The concentration of Rimsulfuron adsorbed in selected soil samples was calculated by equation (1).

$$
\mathrm{C}_{\mathrm{s}}=\frac{\mathrm{V}}{\mathrm{m}}\left(\mathrm{C}_{\mathrm{b}}-\mathrm{C}_{\mathrm{a}}\right)
$$

where, $\mathrm{C}_{\mathrm{s}}=$ concentration of Rimsulfuron adsorbed, $\mathrm{V}=$ volume of the solution, $\mathrm{m}=$ the amount of soil taken in grams, $\mathrm{C}_{\mathrm{a}}=$ equilibrium concentration of the supernatant, $\mathrm{C}_{\mathrm{b}}=$ the equilibrium concentration of blank.

From above equation values of linear isotherm can be written as equation (2):

$$
\mathrm{K}_{\mathrm{d}(\mathrm{ads})}=\frac{\mathrm{C}_{\mathrm{s}}}{\mathrm{C}_{\mathrm{e}}}
$$

where, $K_{d}=$ linear sorption coefficient in $\mathrm{mL} / \mu \mathrm{g}$, $\mathrm{C}_{\mathrm{e}}=$ concentration of Rimsulfuron at equilibrium in $\mu \mathrm{g} \mathrm{ml} / \mathrm{L}$.

The Freundlich equation for all the soil samples can be represented by equation (3):

$$
\mathrm{C}_{\mathrm{s}}=\mathrm{K}_{\mathrm{f}}-\mathrm{C}_{\mathrm{e}} \frac{1}{\mathrm{n}}
$$

where, $\mathrm{C}_{\mathrm{s}}=$ concentration of Rimsulfuron adsorbed, $\mathrm{C}_{\mathrm{e}}=$ equilibrium concentration in $\mu \mathrm{g} \mathrm{m} / \mathrm{L}$,

$\mathrm{K}_{\mathrm{f}}$ and $1 / \mathrm{n}=$ Freundlich constant obtained by using the Freundlich equation in linear form.

$\mathrm{K}_{\text {foc }}$ can be calculated by the equation given below (Equation 4):

$$
\mathrm{K}_{\mathrm{foc}}=\frac{\mathrm{K}_{\mathrm{f}}}{\% \mathrm{C}} \times 100
$$

Similarly, $\mathrm{K}_{\mathrm{oc}}$ and $\mathrm{K}_{\mathrm{om}}$ can be calculated by using equation (5) and (6):

$$
\begin{gathered}
\mathrm{K}_{\mathrm{oc}}=\frac{\mathrm{K}_{\mathrm{d}}}{\% \mathrm{C}} \times 100 \\
\mathrm{~K}_{\mathrm{om}}=\frac{\mathrm{K}_{\mathrm{d}}}{\% \mathrm{OM}} \times 100
\end{gathered}
$$

Gibbs free energy is calculated by the following equation: 


$$
\Delta \mathrm{G}=-\mathrm{RT} \ln \mathrm{K}_{\mathrm{OM}}
$$

where, $\mathrm{R}=$ universal gas constant, $\mathrm{T}=$ temperature in Kelvin. Its value can be used to determine the nature of adsorption or adsorption binding to soil, its value $\leq-40 \mathrm{~kJ} \mathrm{~mol}^{-1}$ represents the physical binding of pesticide with soil.

\section{CONCLUSION}

Pesticides usage in Pakistan is very common and growing at an exponential rate. Unsafe application and misuse of these pesticides is now a major threat to environment and living organisms. Adsorption of Rimsulfuron was largely dependent on soil's characteristic. Organic matter, $\mathrm{pH}$, clay content, total carbon and total nitrogen were found to be most important parameters while studying the sorption of Rimsulfuron. Furthermore, this research additionally established an easy method for removal of pesticide by utilizing activated carbon prepared from sawdust. This method has been found to be superior as compared to other methods of pesticide removal in terms of cost effectiveness along with being environmentfriendly approach. Current results are suggestive of the medium percolation rates of the Rimsulfuron in selected.

\section{REFERENCES}

1. T. James and S. Gaw, Report for Tasman District Council, 2015.

2. K. S. Ahmad, N. Rashid and M. Zakria, J. Chem. Pak. Soc., 2015, 37, 380-389.

3. K. S. Ahmad, N. Rashid, S. Tazaiyen and M. Zakria, J. Chem. Pak. Soc., 2014, 36, 1189-1195. 7p.

4. K. S. Ahmad, N. Rashid, S. Tazaiyen and M. F. Nazar, J. Chem. Pak. Soc., 2013, 35,1018-1025.

5. S. Zhou, X. W. Hua, W. Wei, Y. C. Gu, X. Q. Liu, J. H. Chen, M. G. Chen, Y. T. Xie, S. Zhou, X. D. Meng and Y. Zhang, J. Agric. Food Chem., 2017, 65, 7661-7668.

6. A. Khaliq, M. Shakeel, A. Matloob, S. Hussain, A. Tanveer and G. Murtaza, Phili. J. Crop Sci. (PJCS), 2013, 38, 1-3.

7. M. N. Mushtaq, Z. A. Cheema, A. Khaliq and M. R. Naveed, J. Sci. Food Agric. 2010, 90, 1897-1904.
8. H. Rola, J. Sumisławska and K. Marczewski, J. Plant Prot. Res,. 2009, 49, 179-184.

9. Z. M. Li, Y. Ma, L. Guddat, P. Q. Cheng, J. G. Wang, S. S. Pang, Y. H. Dong, C. M. Lai, L. X. Wang, G. F. Jia and Y. H. Li, Pest Manage Sci., 2012, 68, 618-628.

10. N. Milosevic, S. Qiu, M. Elsner, F. Einsiedl, M. P. Maier, H. K. V. Bensch, H. J. Albrechtsen, P. L. Bjerg, Water Res., 2013, 47, 637-649.

11. M. Shahid, A. Ahmad, S. Khalid, H.F. Siddique, Saeed, M. R. Ashraf, M. Sabir, N .K. Niazi, M. Bilal, S. T. A. Naqvi and I. Bibi, in "Soil Science: Agricultural and Environmental Prospectives", Springer, Cham., 2016, p. 199-229.

12. A. Alamdar, J. H. Syed, R. N. Malik, A. Katsoyiannis, J. Liu, J. Li, G. Zhang and K. C. Jones, Sci Total Environ., 2014, 470, 733-741.

13. A. Mahmood, R. N. Malik, J. Li and G. Zhang, Food Chem Toxicol., 2014, 71, 17-25.

14. M. C. Hermosin and J. Cornejo, Soils, Plants, Aquatic Systems, 2018, 1-10.

15. X. Liu, H. Wu, T. Hu, X. Chen and X. Ding, Environ. Monit. Asses., 2018, 190, 86-89.

16. K. A. Morris, X. Li, D. B. Langston, R. F. Davis, P. Timper and T. L. Grey, Pest. Manage. Sci., 2018, 74, 430-437.

17. A. T. Faria, M. F. Souza, A. B. R. de Jesus Passos, A. A. da Silva, D. V. Silva, J. C. Zanuncio and P.R.R Rocha, Environ. Earth Sci., 2018, 77, 214.

18. C. Mathias, "Adsorption of Organophosphates from Drinking Water Using Activated Carbon from Seed Waste", Doctoral dissertation, The Ohio State University, 2018.

19. C. Rasmussen, K. Heckman, W. R. Wieder, M. Keiluweit, C. R. Lawrence, A. A. Berhe, J. C. Blankinship, S.E. Crow, J. L. Druhan, C. E. H. Pries and E. Marin-Spiotta, Biogeochem., 2018, 137, 297-306.

20. S. Sauve, W. Hendershot and H. E. Allen, Environ. Sci. Technol., 2000, 34, 1125-1131.

21. W. Wang, X. Li, H. Lu, X. Wang and X. Jiang, J. Wenzhou Univ. (Natural Sciences), 2008, 2, 8-11.

22. S. Muhammad, T. Müller, R. G. Joergensen, Biol. Fertil. Soils., 2006, 43, 93-101.

23. J. D. Saritha, T. R. Prakash, M. Madhavi and P. C. Rao, IJCS., 2017, 5, 740-746.

24. R. Jiang, M. Wang and W. Chen, Chemosphere, 2018, 204, 483-491.

25. G. Sheng, C. T. Johnston, B. J. Teppen and S. A. Boyd, J. Agric. Food Chem., 2001. 49, 2899-2907.

26. F. Sadegh-Zadeh, S. A. Wahid and B. Jalili, $A d v$. Environ. Technol., 2017. 2, 119-132.

27. K. S. Ahmad, Int. J. Environ. Sci. Technol., 2018. 1-12.

28. K. S. Ahmad, Environ. Earth Sci., 2018. 77, 437.

29. K. S. Ahmad, Environ. Monit. Assess., 2018. 190, 737.

30. S. Iftikhar, K. S. Ahmad and M. M. Gul, Comm. Soil Sci. Plant Anal., 2018. 1-14.

31. K. S. Ahmad, Soil Sed. Contam. Int. J., 2018. 1-16. 
